ISSN 1112-9867

Available online at http://www.jfas.info

\title{
INVESTIGATING ATRIUM IN HOT AND HUMID CLIMATE AND PROVIDING STRATEGIES FOR IMPROVING ITS QUALITY IN ADMINISTRATIVE USE (CASE STUDY: BANK OF SHANGHAI, CHINA)
}

\author{
M. Majidaii ${ }^{*}$, S. Z. Galughahi ${ }^{2}$, M. Alishah $^{3}$, S. R. Rasuli ${ }^{3}$ \\ ${ }^{1}$ Qazvin Branch, Islamic Azad University, Qazvin, Iran \\ ${ }^{2}$ SamaUnite, Sari Branch, Islamic Azad University, Sari, Iran \\ ${ }^{3}$ Sari Branch, Islamic Azad University, Sari, Iran
}

Published online: 18 June 2016

\begin{abstract}
The energy crisis at present time has made the importance of paying attention to sustainable architecture and reduction of renewable energy consumption inevitable. Given that architecture plays an important role in urban construction, it has a heavy responsibility because more than $50 \%$ of the world's energy is devoted to this area. Therefore, paying attention to reducing energy consumption and promoting saving technologies to reduce environmental pollution should be placed on the agenda of designers. The present study aims to investigate performance of atrium as an example of sustainable architecture in hot and humid climate and to identify strategies to improve its performance in the mentioned climate. Atrium has thermal comfort space since the old time by two methods of greenhouse effect and chimney effect. Now these questions are raised: What impact does atrium have in terms of performance in reducing energy consumption in buildings and how is the performance of atrium in the hot and humid climate, and how it can be improved? The presented research investigates atrium and its role in reducing energy consumption by benefiting library studies and analytical method.
\end{abstract}

Author Correspondence, e-mail: Ngn.march@gmail.com

doi: http://dx.doi.org/10.4314/jfas.v8i2s.117 
Research findings indicate that performance of lateral atrium in humid and moderate climates is better than upper side atrium and its performance can be improved using delay spray and shadow system methods.

Keywords: Sustainable architecture, Atrium, hot and humid climate, administrative use.

\section{INTRODUCTION}

Since the time human could build habitats for himself and have shelter in foliage and house on the ground floor, tried to have comfort and be protected from animals, birds and other humans. From the very beginning human beings were aware that they needed to be connected with their environment. Modern period coincided with World Wars I and II. Man followed uncontrolled mass production of housing to respond his needs. Technology and industry growth caused excessive increase in use of resources. Human beings found that energy resources will end someday and tried to respond their needs through measures that were rooted in tradition, but with new thinking in accordance with the technology. In the meantime man was faced with huge giant buildings that needed transparent central spaces to provide natural light and warmth to do this transition and this space was named Atrium. Atrium with a history of several thousand years is seen in various forms with open roof, in all climates and has been welcomed in the last century with glass roof and different features, despite high heat dissipation and interference comfort conditions, in public buildings for acceptance and living, internal lighting and inside green spaces.In fact atrium can be an example of sustainable architecture, the most important principles of sustainable architecture is optimal usage of climate in architecture design; in other words sustainable architecture design describes architecture as full knowledge of the environment. Observing the climatic conditions in architecture is followed by savings in energy consumption (Shoaii and Ishmael, 2011) and this is one of the most controversial issues of contemporary architecture. The issue that each building must be able to interact with the environments in which it is located is not debatable. What is challenging is type of this relationship. Today, the idea of sustainable architecture has been raised to respond this question (Asadpour, 1, 2006). Addressing sustainable architecture and tools of formation of such an approach in design of architecture leads us towards local architecture and sustainable approach in comparison and measurement with each other, so that its teachings for design of today architectural can be extracted, (Armaghan, 20,2009). With more engagement in the matter, we find that the concept of 
sustainable architecture rooted in the old customs and old culture human and traditional life it is manifested in form of honoring and dignifying nature and sources. Thus, it can be said that activities of last decades of the twentieth century are attempt to revive these ancient concepts (Musavi, 19, 2004). Local architecture in an area is considered as a part of national capital of every nation that includes their local beliefs, values and knowledge, and it is result of centuries of trial and error in the natural environment, often transmitted orally from one generation to the next, (Emadi, 1999, 1). In dealing with all sets and units of local architecture, it seems that these sets have been good examples for sustainability in their time and place. The aim of this study is to identify a strategy that in addition to bringing comfort for residents, according to the climate, saves the energy consumption with environmental goals. Given these objectives, not only Atrium can be designed in such a way that has low power dissipation, but also play a new role in reducing energy consumption in the form of natural heating and cooling and passive solar function; and given its thermal interface characteristic, provides possibility of increasing levels of internal openings to get more natural light .This study aiming to evaluate the performance of Atrium in hot and humid climate, in order to increase the quality of research, attempted to study and analyze a sample of using Atrium in Bank of Hong Kong in China, as an example of successful performance of Atrium in office building.

\section{Problem statement}

Climate is one of the most important environmental factors that play a key role in behavior and general state of human. One of the important effects of climate on human life is construction of buildings in accordance with these terms and creating thermal comfort conditions by climatic parameters. In all climates, buildings that are built on the principles of ecological design, the need for mechanical heating and cooling are reduced to a minimum, and instead natural energy around the buildings is used. This saves power consumption and is helpful in optimal use of environmental conditions in creating comfort for living inside buildings and creating comfortable and favorable conditions of life and providing security of residents against unfavorable environmental and climatic conditions are integral principles of Architecture and Construction (Moradi, 1384, 29).Today, with development of technology, necessity of paying attention to construction in accordance with the principles of climate is of particular importance (Ghanbari and Tillmi, 2013). Technology growth after the Industrial Revolution, followed by easier access to fossil fuels has created a fundamental shifts in architecturethat the most important one is 
forgetting architectural patterns that were created in order to adapt to the climate. In the modern world people believe that life is impossible without these energies, but course of traditional architecture demonstrates that the past architecture has always been to integrate with nature, (Ghanbari and Sharif Khwaja Pasha, 2013), so that today, despite use of modern technology and high cost of houses construction, it is seen that we have not been able to provide comfort at houses. This is due to the crisis of identity in architecture of today and blind imitation of Western architecture, (Pour Ismail, 2010). But the study of indigenous building in any climate, clearly shows the fact that all local buildings are designed and constructed entirely based on climatic principles to maximize use of natural energies and cope with oppressive cold and heat which is fully aligned with the culture of each region and the local and vernacular architecture has been described (Qobadian, 2006). The issue of climatein discussion of sustainable development is fundamental and decisive because the subject of sustainable development is saving energy, especially fossil and renewable energy; therefore, the climatic design of buildings and urban structure has an important and decisive role in reducing fuel consumption and thus its preserve for future generations. The advent of technology and the use of fossil energy and mechanical devices, almost two centuries, the local climate and disruptions in the design of buildings and cities have created special and in this way, the issue of excessive use of fossil energy sources on the one hand and on the other hand environmental pollution resulting from its use, come in for serious and life-threatening. The advent of technology and possibility of using fossil energies and mechanical devices for almost two centuries has caused disruptions in climatic and local design buildings and particularly cities and thereby, the issue of excessive use of fossil energy sources on the one hand and environmental pollution resulting from its use on the other hand has become serious and life-threatening issue. One of the consequences of modern world is human's being away from nature. Sustainable development is trying to solve this crisis with a new approach and solving this crisis in the field of architecture from a particular view is subject to creating a different attitude to his living space. In discussing sustainable development, with study of local buildings in every climate it is found clearly that all local buildings are designed and built completely based on climatic principles and line with maximum use of natural energies and dealing with annoying heat; and this is fully consistent with the culture of people in each region and vernacular local architecture is defined. Renewed attention to climatic design and return to local architecture and urbanization has been raised and invites practitioners and specialists in 
architecture and urbanism to address this matter seriously. Since atrium, as one of the important examples of sustainable architecture, causes thermal comfort in space through two greenhouse effect and chimney effect from the distant past and in diverse climates, two following questions are raised:

-What role does atrium play in terms of performance in reducing energy consumption in buildings?

-How is the performance of atrium in hot and humid climate?

\section{Background}

Table1. Summary of studies done in (investigating atrium in the hot and humid climate and providing strategies for improving its quality in administrative use). (Source: the author, 1394)

\begin{tabular}{|c|c|c|c|}
\hline Results & subject & researcher & \\
\hline $\begin{array}{l}\text { Uncontrolled population growth has catastrophic effects } \\
\text { on the Earth's natural habitates and urban sprawl led to } \\
\text { irresponsible consumption of energy. }\end{array}$ & $\begin{array}{c}\text { Investigating } \\
\text { climatic patterns in } \\
\text { warm and dry } \\
\text { climate and its } \\
\text { impact in reducing } \\
\text { energy } \\
\text { consumption }\end{array}$ & $\begin{array}{l}\text { Tanhaiian } \\
\text { and Kazemi } \\
\text { (2012) }\end{array}$ & 1 \\
\hline $\begin{array}{l}\text { Today, the subject of sustainability has made sustainable } \\
\text { architecture teaching face with numerous problems } \\
\text { including blurred identity, limited skills, and lack of } \\
\text { proper models. In study performed after studying the } \\
\text { environmental crisis, concept and history of sustainable } \\
\text { architecture two models sustainability education and } \\
\text { finally, investigating challenges of architecture teaching } \\
\text { in the world studied architecture teaching in Iran. }\end{array}$ & $\begin{array}{l}\text { The need for a } \\
\text { flexible system of } \\
\text { architecture } \\
\text { teaching to meet } \\
\text { the global and } \\
\text { local challenges of } \\
\text { sustainability }\end{array}$ & $\begin{array}{l}\text { Azaizi } \\
(2010)\end{array}$ & 2 \\
\hline $\begin{array}{l}\text { Sustainable architecture, in other words the same } \\
\text { architecture compatible with climate, has minimized } \\
\text { resource consumption and enabled use of natural } \\
\text { resources. And architecture design according to climate }\end{array}$ & $\begin{array}{l}\text { Building harmony } \\
\text { with climatic } \\
\text { factors in } \\
\text { achieving }\end{array}$ & $\begin{array}{l}\text { Shosii and } \\
\text { Arab } \\
\text { Ismaili } \\
\text { (2011) }\end{array}$ & 3 \\
\hline
\end{tabular}




\begin{tabular}{|c|c|c|c|}
\hline $\begin{array}{l}\text { issues and its applicability in designing and building } \\
\text { structure considering all modern science and technology } \\
\text { to achieve sustainable design. }\end{array}$ & sustainable design & & \\
\hline $\begin{array}{l}\text { Raising the cost of energy supply in recent decades has } \\
\text { caused climate comfort in buildings considering climatic } \\
\text { conditions of each region to be one of the most important } \\
\text { concerns of architectures. }\end{array}$ & $\begin{array}{c}\text { Evaluation of } \\
\text { climatic comfort } \\
\text { for designing } \\
\text { buildings in } \\
\text { harmony with the } \\
\text { climate }\end{array}$ & $\begin{array}{l}\text { Mir Mousavi } \\
\text { and Shafiee } \\
\qquad(2011)\end{array}$ & 4 \\
\hline $\begin{array}{l}\text { Development that is not environmentally friendly is not } \\
\text { sustainable. Today, many dangers threaten the } \\
\text { environment. Among methods for sustainable } \\
\text { development, is the use of renewable energies such as } \\
\text { solar, geothermal, wind and so on. Iran is rich in } \\
\text { renewable and non-renewable energy sources. Iran's } \\
\text { geographical position has caused massive source of } \\
\text { renewable energy to be free and environmentally } \\
\text { friendly }\end{array}$ & $\begin{array}{l}\text { Sustainable } \\
\text { development in } \\
\text { Firouzkouh city } \\
\text { using wind energy }\end{array}$ & $\begin{array}{c}\text { Gandomkar } \\
\text { (2009) }\end{array}$ & 5 \\
\hline $\begin{array}{l}\text { Raising the cost of energy supply in recent decades has } \\
\text { caused climate comfort in buildings considering climatic } \\
\text { conditions of each region to be one of the most important } \\
\text { concerns of architectures }\end{array}$ & $\begin{array}{c}\text { Evaluation of } \\
\text { climatic comfort } \\
\text { for designing } \\
\text { buildings in } \\
\text { harmony with the } \\
\text { climate }\end{array}$ & $\begin{array}{l}\text { Mir Mousavi } \\
\text { and Shafiee } \\
\qquad(2011)\end{array}$ & 6 \\
\hline
\end{tabular}

\section{RESEARCH METHODOLOGY}

Examining sustainability in the field of architecture is possible through proper understanding and application of methods to achieve the goals of sustainability according to that climate. In this 
study it is tried to investigate performance of atrium in hot and humid climate with a case study in Hong Kong bank, based on descriptive-analytic and data collection through library method.

\section{Theoretical Foundations}

\section{Sustainable Architecture}

The main root of environmental protection movement and sustainable architecture dates back to the nineteenth century. John Ruskin, William Morris, Richard Latabi are the pioneers of sustainable architecture movement. In his book of "The Seven Lamps of Architecture" Ruskin says that to achieve growth and progress harmonic order in nature can be taken as model. Morris recommended returning to suburban green space, self-sufficiency and revitalization of local industries. Latab, in one of his eloquent statements, asked architects to appreciate the order and beauty of nature. All these pioneers have used the word "nature" and today the only word that can well be replaced by this term is "sustainable architecture", (Soflaee, 63,2004). Application of sustainability concepts in architecture has opened a new discussion called "sustainable architecture" or "ecological architecture "or "green architecture "or "ecological architecture" all of which have the same meaning and indicate environmentally friendly architecture,(Qiasvand, 4, 2007). Sustainability without intermediate is the same path that architecture should access in near future. This type of architecture should be associated with human feelings towards nature. How we design our houses and choose their materials is one of the most important issues that affect future of our buildings, (Soflaee, 63, 2004). All the designs done in conjunction with sustainable systems should be able to somehow provide predictions for the future. For example, a building must be designed so that reuse of it or its components is considered. This foresight is also used to meet the needs of the future generations, (Soleimani, 2,2008) and principles extracted based on natural conditions and factors by trial and error over thousands of years been can be important criteria for decision-making by contemporary designers. Configuration, density, alignment, rotation (relations between spaces), roof shape, surfaces, openings, shadowing agents and materials have been selected as the main theme for the architectural principles and elements in different climates.

\section{Principles of sustainable architecture}

The principles that must be met for a building is classified as sustainable buildings are as follows: 1-Energy Saving

2-Coordination with the climate 
3-Reduction of the use of new resources

4- Meeting the needs of residents

5-Coordinate with site

6-Holism (Qiasvnd, 4, 2006)

This study aims to investigate design of sustainable office building with the purpose of saving energy consumption and application of atrium as a strategy to achieve this with bringing examples.

Factors contributing to the sustainability of office buildings

An office building can have the condition of sustainability if following factors are considered in designing:

-Natural air conditioning or a combination of natural and mechanical one

-Having appropriate daylight

-Shading equipment special for the control of sun light

-Appropriate distribution of light within the building

-Passive systems

-Temperature control capacity of building

-Stud effect conditioning in the atriums

-Air cooling transition ceilings (Graham, 2003).

Given the important role of natural light on mental health and productivity of employees and personnel in offices, it is essential to use it in the offices with architectural tricks. Due to sound pollution, noise and external disturbing factors, use of opening windows in offices is not correct, on the other hand using all glass facades for offices, due to causing difficulties in reaching thermal comfort are not suitable. This need to natural light and oxygen required to create thermal comfort has led to considering open spaces inside and around the building as respiratory lungs.

\section{Atrium's historical background}

Historically, atrium is a term used to open yards or rooms with opening inside the Roman house, which has been a pond to collect rainwater. Besides interior spaces, atrium has had the role of providing fresh air and controlled light. Medieval Basilica church yards hat religious groups used for gatherings called as this. In the eighteenth century after learning the properties of the glass to attract and retain heat, these spaces with glass walls and ceilings and wooden frames were used by Dutch botanists. During the nineteenth century, following the production of steel pieces and 
creating large openings, great glass spaces were designed and produced for holding exhibitions and stores of agricultural and industrial products. The most famous and oldest forms of them include Royal Pavilion in Brighton, Crystal Palace and Milan Gallery. At the beginning of the twentieth century with the beginning of modern movement in architecture, features of the atrium space caused that Lloyd Wright make it common for focus of employees and creating solidarity between them in most public, commercial and institutional buildings in order for sitting of clients, travelers and meeting of people and students. In this regard, the designers in accordance with form of the main building, entered atrium as central, integrated, leaner, connectional and environmental in their plans and used it. A large part of these intermediate spaces were glass surfaces that provided light and vision for the people, adjacent spaces and growth of plants inside. Following the energy crisis and environmental problems and the need for emphasis on sustainable development, designing artificial environments was considered in a comprehensive process including ecology, environment and energy source. Therefore, this review on the one hand considers physical conditions of atrium in relation to external and internal environments and utilizing solar energy absorption capability and maintaining it in atrium; on the other hand functional programs encourages designers to provide human comfort by reducing energy consumption and waste, (Mokhtari and Vali beig, 3,2011).

\section{Physical examination of Atrium}

In terms of physic, atriums are combination of transparent, semitransparent and opaque surfaces which surround openings, hallways, exterior walls and interior space atrium. Geometric features of atrium and materials and implementation details used in it, have significant impact in the manner and amount of light and energy receiving, heat dissipation, ecosystem problems, thermal stratification, and natural ventilation. Each of the above items are parameters whose combination specifies the final efficiency of atriums and cannot be determined or set by conventional methods separately, rather after determining performance scope of each, other parameters should be coordinated with each other.

Form and geometric structure configuration of atrium is function of several factors:

-Form of main building, deployment of adjacent light spaces and required surface for interior landscaping

-Amount of brightness and energy receiving from sun's energy for the use of passive susceptibility of Atrium 
-Reduction of the effect of cold wind and heat exchange through transparent surfaces, glass support structures and exterior walls (MADI, 2007, 98).

\section{Investigating atrium performance in terms of energy savings and the possibility of energy holding in office buildings}

Creating an atrium in a building, especially with public and administrative use can cause saving the four forms:

1-Atrium as a buffer space, in form of thermal interface typically has 18-15 degrees of internal temperature, but the temperature of atrium itself changes with fluctuations in temperature of surrounding environment and time lag. Adjacent spaces of atrium reduce the strong changes of protected environment and decrease heat loss resultant from its transparent surfaces. Amount of this savings depends on the internal temperature of atrium, conditions of hermetisation and ventilation of atrium, thermal conductivity coefficient of its constituent elements and degree of insulation of its surfaces.

2-By creating atrium, windows of internal adjacent spaces get large as required and allowing natural light penetration and reduce electricity consumption.

3-With pre-heating or pre-cooling fresh air, heating and cooling load of building decreases.

4- If atrium has heat storage surfaces and is turned toward the south, it passively uses the energy of key factors that need to be considered in the ability of atrium to create a buffer space with heat storage source to adjacent spaces, (Gratia, E. and Deherd, A. p19).

- Atrium type according to climatic circumstances

- Type of glassing and degree of its insulation

- Structure of glassing

- Thermal capacity of the inner surfaces:

Energy saving in Atrium adjacent spaces reduces heating needs and in contrast some of the atriums reduce heating needs of building due to their nature of the mediatory but this ability also depends on Atrium internal heat and this heat is associated with the following:

-Ratio of outer surface of the atrium windows to the walls surface

-Tune of heat transfer from wall of dividing atrium from main structure that is usually determined by ratio of internal windows surface to whole surface of wall

- Orientation, slope and tune of heat transfer through outer windows of Atrium (Gratia, E. and Deherd, A. p19). 


\section{Investigating atrium performance in hot and humid climate}

Atrium is typically an empty enclosed space that is created vertically and multi-storey height. Modern atriums are identified by their geometry, physical characteristics of their holes, and physical characteristics of the wall between the atrium and adjacent spaces. Atrium is incorporated more and more in the environment structure, regardless of cultural and climatic conditions. Atrium is seen in many types of buildings including offices, hotels, hospitals and shopping centers. Atrium space is typically made of large glass walls and ceiling, (Abudullah, 2009, 432.)

Given the characteristic of high dispersion in glass material for both sun and heat, indoor thermal environment of Atrium is greatly affected by outdoor conditions. Obviously, benefits of the Atrium is more clear particularly in the winter when they create control environment friendly space and also there is natural light and increase of useful heat from sunlight in high-latitude regions. However, in tropical climates, most of the time satrium is in excess heat conditions. These high risks of heat disorders and related problems have intensified in the wake of the heat. Not only the air temperature inside can be higher than the external air temperature, but also a relatively high proportion of solar radiation absorbed by Atrium cover increases the average radiation temperature of the inner surface that led to the rise in temperature inside the atrium, (Ibid.). These have high risk of heat disorders and problems related to intensified heat. In addition, when transparency (being glassy) of walls and ceilings gets more, the buoyancy force generated by the heat of the sun gets important, and this can lead to significant thermal stratification that is difficult to control. In the atrium to some extent conditional, although the heat exacerbate problems may be resolved at lower levels, high levels particularly under-roof area is very hot all the year. All these cause thermal adverse conditions that result in more bothering of residents, especially on the top floor adjacent to the atrium, (Abudullah, 2009, 438). Many researchers have shown that guidelines of main designing for hot and humid weather reduce heat absorption through building envelope and making air movement. One of less effective cooling methods that can possibly reduce solar heat absorption from roof of the building is evaporative spray cooler. Theoretically, when a non-saturated air flow is surrounded by a wet surface, some of its water evaporates. The same air flow on the humid air flow glass roof provides the heat necessary for evaporation that the so-called evaporative cooling occurs, (Ibid). 
The air transfers heat by convection or radiation, where a lot of evaporative heat is wasted during transfer of evaporative liquid mass, as a result prevents overheating of the roof and interior of the building. Another simple, effective and inexpensive method for avoiding unnecessary sun exposure and sun glare that exacerbates light sensitivity in buildings is using enough shadow systems. They include fixed shadow devices, manual, automatic, portable, domestic and foreign ones. This implies that shadow systems must be able to control and regulate the sunlight through transparency (glassy) ceiling and atrium view, (Abudullah, 2009).

\section{Investigating performance of atrium in Shanghai Bank of China}

Shanghai latitude is like New Orleans, Brisbane and Cairo, its climate is classified as subtropical humid. In one of the components of the Hongkong Bank is Foster's office, Atrium is suppliers of natural light in the building. Supply of light in this building is through reflection from surface of two very large mirrors. The plate collecting sunlight outside is made of hundreds of small mirrors, which follow the path of the sun and reflect it toward the concave mirror at the top atrium. This concave mirror, directs light into space and even below the glass floor of the building. The initial sketch of Norman Foster shows direction of the light into the basement in the best way. (Theguardian.com)

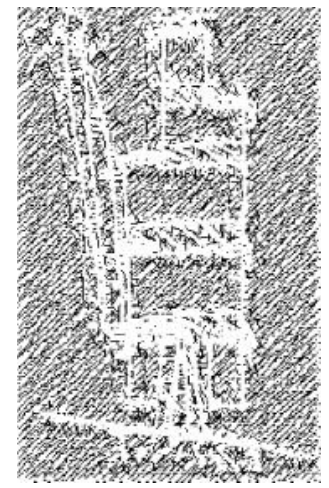

Fig.1. Primary etude of designer and display of light direction into the basement, (source: www.archdaily.com)

Wonderful adjustment of natural light in the institute work of Arab has made possible Jean Nouvel's Fest shutter thousands sensitive, controlled by computer. This building is designed with the aim of bringing sunlight into the heart of tower through the bank's atrium space and towards the bottom side of the field. This resulted in insertion of one of the more interesting features of 
bank that is an array of mirror known as the solar panel system. One of the solar panels is placed on top of Atrium and the other is parallel to it attached to the exterior of façade of buildings on the south side. Exterior façade panel follow the sun movements throughout the year and reflects sun light and reflects sunlight backwards that is the mirror row above the head of employee son eleventh floor. In this section it is noteworthy that, although the warm air in upper atrium improves upward flow, at the same time leads to unpleasant thermal conditions for residents of the upper floors. The main reason for the intensification of heat is excessive penetration of solar radiation to atrium through transparent surfaces. Therefore, control of solar radiation is an essential parameter which is increasingly done by connecting shadow devices and evaporative cooling systems, that in this building solar panels are used in form of a mirror in order for reflection, (Ibid.).

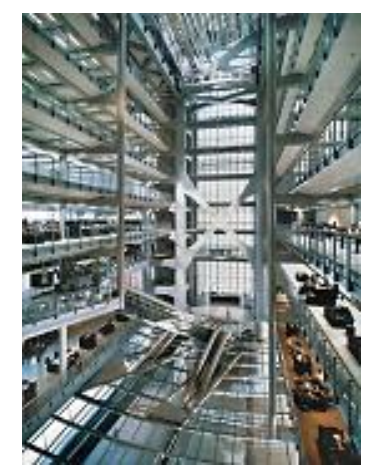

Fig.2. Transfer of light into the solar panels (Source: ibid).

Internal mirror that form shell curved screen throughout the upper length of atrium bar, reflect light through the intrados glass downwards that is atrium and into the basement field. Shelf of placing each mirror is equipped with an electric motor and computer control and allows the mirrors to follow the sun's movement; of course the aim is not to neutralize the daily fluctuation of East to West sun; this means that as the day progressed the sun goes down from one side of atrium and passes from field of ground floor and goes up from other side of atrium. More precisely, with changes and measures planned for row of placing mirrors, they follow the sun through seasonal changes. In Hong Kong goes beyond a 45 degrees side at between summer and mid-winter. In the meantime, there is an advanced program that is able to direct sunlight during similar path every day of year by being fed into a personal computer; these shelves impose little adjustments every hour, (Theguardian.com). 


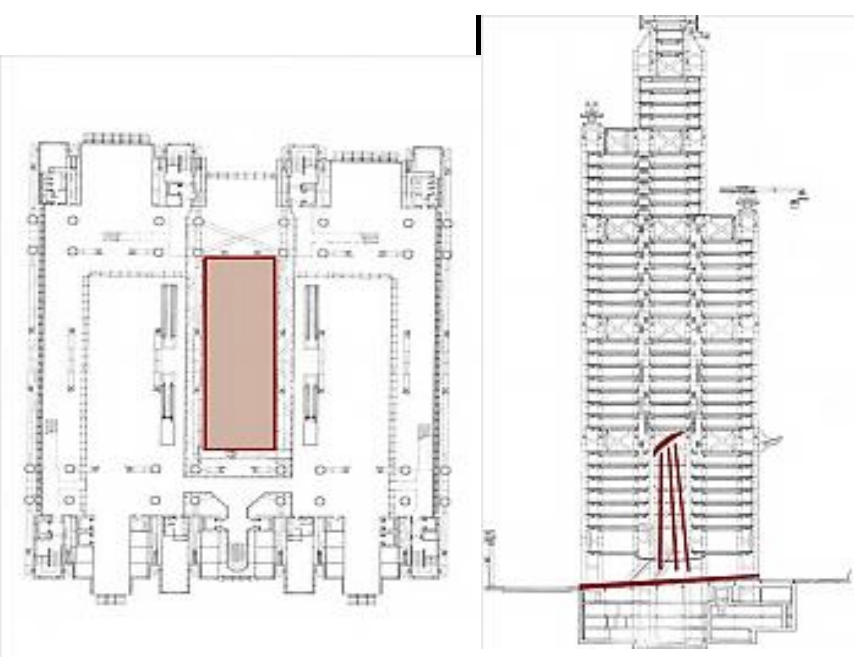

Fig.3. transfer of light to the basement by Atrium, (Source: ibid.)

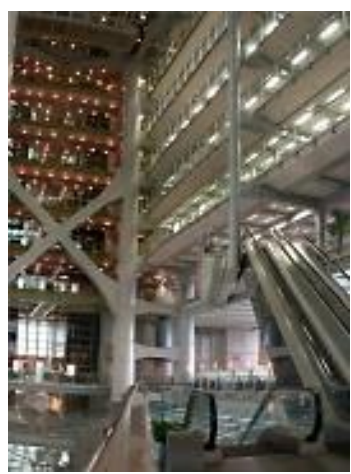

Fig.4. Display of transmitted light to the interior space of building by Atrium, (Source: ibid).

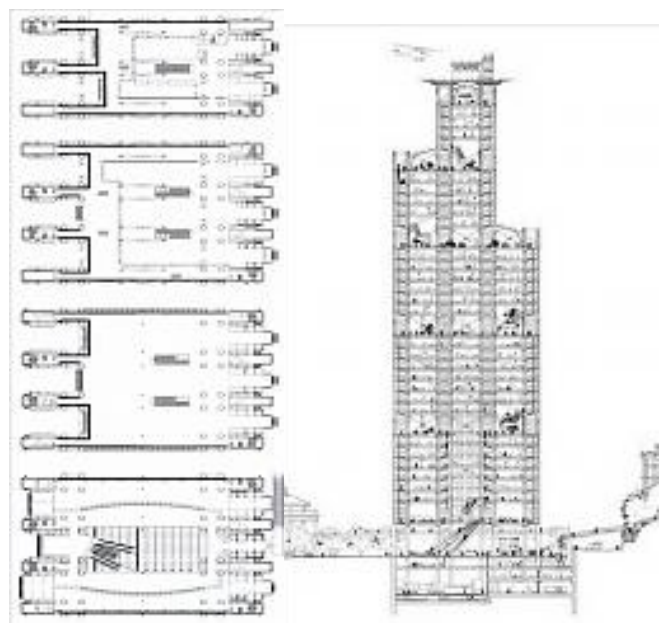

Fig.5. Display of measures intended to implement Atrium in plan and cross-section (Source: ibid). 
Using a special automated machine that supplies and transfers measured amount of energy for operation mechanisms or other system, leads directing beams in a way that not only the light does not bother the eyes of employees, but also the internal obstacles to deliver the highest possible sun's light to light needing place are resolved. Paying attention to this factor in the design of offices by designer causes that in addition to meeting the energy needs of the building, by taking some measures in order to use them correctly mental health of employees, improvement of the quality of their performance and satisfaction from the work environment are obtained. And this is simultaneous satisfaction of human and nature needs completely in line with the objectives of sustainable architecture.

\section{CONCLUSION}

As noted in the discussion, the issue of architectural design approach in a sustainable development and solidarity of building components as a system related to the environment is of utmost importance. Use of atrium in modern architecture acts as breathing lungs of a building. And by providing lighting and interior space ventilation can be an appropriate response to contemporary sustainable architecture. By creating an interior space, atrium protects the building against unfavorable weather conditions in open space protection. Providing solar absorption and enough light and also improved thermal comfort features are some of the benefits of Atrium. All of these features are more common in office buildings in order to provide more usable areas. In the hot and humid climate, because of the need for proper ventilation and exposure in accordance with ventilation arrangements, atrium is a good choice in designing since if it is designed properly, can be very efficient in the way of achieving the goals of sustainable architecture. According to the studies conducted in the Bank of Shanghai in china, realization of the followings in building is observed:

-Separating, defining and scoping spaces and designing various spaces in offices

-Building flexibility by creating a microclimate with respect to temperature variations.

- Minimizing consumption of non-renewable energies

-Preventing heat loss in the building

-Reducing power consumption with increased light absorption of windows of atrium adjacent spaces 
-Possibility of entering fresh air and correct application of it in different seasons and consequently more decline of wasteful energy consumption

-Air conditioning of central space in the building with entering fresh in building and removing contaminated air from the other side

-Dynamism and vitality of space because of the transparency and enhanced visual communications. All of these cases are observed with intelligence of designer, and in order to create a sustainable office building in the bank studied and significantly saves energy consumption and respecting bioclimatic issues. It should be noted that the advantages of Atrium is not limited only to savings in energy consumption and its environmental benefits encourages designers to add it to their building. It is hoped this study, by expressing key features in reducing energy consumption by examining case study can take effective step in use of the atrium with lower consumption of energy, so that there is foresight and planning for evolution in application of atriums with better features that reduce energy consumption and costs.

\section{REFERENCES}

[1] Asad Pour, A. Sustainable patterns in architecture of Iran desert. Journal of Iranian architecture. 2006, 25.

[2] Armaghan M, Gorji Mahlabani Y. The values of vernacular Iranian architecture in relation to sustainable architecture approach, Journal of Housing and villages, 2009, 126, 520- 535.

[3] Pour Ismail, M. (2010). Study of design principles and climatic structural elements in Iranian houses (cold and mountainous climate). Regional Conference of Iranian House, Islamic Azad University of Gonbad-e Qavus, Gonbad-e Qavus.

[4] Tanhaiian, V., Kazemi, M., (2012). Study of climatic patterns in hot and dry region and its impact on reduction of energy consumption in designing. First National Conference on ideas and new technologies in architecture, the Association of Architects of Tabriz.

[5] Qyasvnd, J. Architecture of the environment, sustainable development. Journal of Civil Engineering, 2007, 45.

[6] Qyasvnd, J. Interaction of Architecture and Renewable Energy (sustainable). Journal of Civil Engineering, 2006, 38.

[7] Ghanbari Tillm , Z. (2013). Providing solutions in climatic designing in temperate and humid areas based on the principles of sustainable architecture (Case Study: south bank of the Caspian 
Sea)", National Conference on sustainable architecture and urban development, construction companies of desert, Bukan.

[8] Ghanbari, S., Sharif Khwaja Pasha, S., (2012). Modeling of local architects in designing residential buildings of Gilan. First National Conference on ideas and new technologies in architecture, the Association of Architects ofTabriz.

[9] Qobadian, V., (2006). Climatic investigatingof traditional buildings in Iran. Tehran, Tehran University Press.

[10] Soflaee, F. An investigation of the concepts and practices of sustainable architecture. Journal of Abadi, 2004, 42, 63.

[11] Soleimani, M. Land and sustainable architecture. Architecture and culture journal, 2008, 33.

[12] Shoaii, Hamidreza, Arab Ismaili, N., (2011). Harmonyof building with climatic factors in achieving sustainable design.

[13] Azizi, Sh. Necessity of flexiblesystem inarchitectureteaching torespond the global local challenges of sustainability. Journal of city identity, 2010, 6. 43.

[14] Emadi, M. H, Abbasi, E. Periodical of indigenous knowledge and development.

[15] Gandomkar, A. Sustainable Development in Firouzkouh city using wind energy. Physical Geography Quarterly, 1999, 6, 73.

[16] Mokhtari, M., Vli beig, N., (2011). Atrium, an strategy to keep energy in designing sustainable office buildings. First National Conference on Civil and sustainable development.

[17] Modi, H., Mofidi, M., (2007). Atrium, symbol of sustainable architecture. The sixth national conference on Iran's energy, Proceedings

[18]-Mousavi, S. Ecology in the architecture of Norman Foster. Journal of Architecture, 2004, 26.

[19] Mir Mousavi, H., Shafiee, Sh., (2011). Evaluation of climatic comfort for building design in harmony with the climate of Tehran Case Study, National Conference on the structure, Azad University of Chalus.

[20] Baharvand,M., Thermal performance of Tropical Atrium, Environment and Climate technologies, 2013, 128-144.

[21] Graham, F., Shepperd, R., 2003. The Green Buildings Pay, Editted by Edward Brain.

[22] Gratia, E. and Deherd, A. Solar Energy in European office Buildings, Mid-Career Education, erg/ucd/ie/mid_career/pdfs/tech_mod. 
[23] Halid A., Field study on indoor thermal environment in an atrium in tropical climates, Building and environment, 2009, 431-436.

[24] www.theguardian.com/last access: January11, 2016.

[25] www.archdaily.com/last access/January 08, 2016.

\section{How to cite this article:}

Majidaii M, Galughahi SZ, Alishah M, Rasuli SR, Investigating atrium in hot and humid climate and providing strategies for improving its quality in administrative use (case study: bank of shanghai, china). J. Fundam. Appl. Sci., 2016, 8(2S), 799-815. 